\title{
Physiological changes in response to apnea impact the timing of motor representations: a preliminary study
}

\author{
Franck Di Rienzo ${ }^{1 *}$, Nady Hoyek ${ }^{1}$, Christian Collet ${ }^{1}$ and Aymeric Guillot ${ }^{1,2}$
}

\begin{abstract}
Background: Reduced physiological arousal in response to breath-holding affects internal clock processes, leading swimmers to underestimate the time spent under apnea. We investigated whether reduced physiological arousal during static apnea was likely to affect the temporal organization of motor imagery (MI).

Methods: Fourteen inter-regional to national breath-holding athletes mentally and physically performed two $15 \mathrm{~m}$ swimming tasks of identical durations. They performed the two sequences in a counterbalanced order, the first while breathing normally using a scuba, the second under apnea. We assessed MI duration immediately after completion of the corresponding task. Athletes performed MI with and without holding breath.

Results: Ml durations (26.1 $\mathrm{s} \pm 8.22$ ) were significantly shorter than actual durations (29.7 $\mathrm{s} \pm 7.6$ ) without holding breath. Apnea increased $\mathrm{MI}$ durations by $10 \%( \pm 5 \%)$. Heart rate decrease in response to breath-holding correlated with MI durations increase $(p<.01)$. Under apnea, participants achieved temporal congruence between MI and PP only when performing Ml of the apnea swimming task. Self-report data indicated greater ease when MI was performed in a physiological arousal state congruent with that of the corresponding motor task.

Conclusions: Physiological arousal affected the durations of Ml through its effects on internal clock processes and by impacting the congruency in physiological body states between overt and covert motor performance. Present findings have potential implications with regards to the possibility of preventing underestimation of durations spent under a state of reduced physiological arousal.
\end{abstract}

Keywords: Mental chronometry, Motor imagery, Apnea, Heart rate, Internal clock

\section{Introduction}

Motor Imagery (MI) is the mental representation of a motor act without engaging in its actual execution. A large body of neuroscience research supports that MI and physical practice (PP) of the same task share overlapping neural substrates [1-4], and involve functionally equivalent neural processes [5-8]. As well, behavioral research provided strong evidence for a temporal congruence between the temporal structure of MI and the temporal parameters of the corresponding motor performance, reflecting the involvement of common planning

\footnotetext{
*Correspondence: franck.di-rienzo@univ-lyon1.fr

'Centre de Recherche et d'Innovation sur le Sport, EA 647, Université de Lyon, Université Claude Bernard, Lyon 1, Performance Motrice, Mentale et du Matériel (P3M), 27-29 Boulevard du 11 Novembre 1918, Villeurbanne, Cedex 69622, France

Full list of author information is available at the end of the article
}

and programming strategies [9]. Recently, Guillot et al. [10] reviewed the key-components that may affect the durations of MI, i.e., factors that promote temporal congruence or conversely yield to consistent overestimation or underestimation of PP durations. Interestingly, they specifically highlighted the selective influence of several external factors on MI durations. For instance, the characteristics of the motor skill are likely to alter the temporal congruence between MI and PP durations (i.e., shortlasting motor sequences are usually overestimated, whereas long-lasting and cyclical motor skills tend to be underestimated). Similarly, complex motor sequences require greater time to be mentally rehearsed compared to physically executed $[9,11,12]$. Finally, a proportional increase in MI durations was found along with the intensity of the mental effort [13-15]. 
While some intrinsic features of the task might impact its imagined duration, the sport imagery literature acknowledges that the construction of the temporal organization of MI is primarily based on the temporal parameters of the corresponding motor performance $[10,16,17]$. Indeed, actual motor experiences participate to the central elaboration of forward models [18], i.e., an internal simulation of the movement derived from the efferent copy of the motor command, predicting future body states and stimulating the sensory consequences of the expected actions [18-21]. Accordingly, central processing of MI involves the forward modeling of the corresponding action, from which substantial information about its spatial and temporal features is obtained [18,21-23]. Albeit primarily showed in chronometric experiments, this claim is also supported by brain imaging data. For instance, Lorey et al. [24] stated that:

"The functional equivalence of action states is due mostly to internal estimations of the expected sensory feedback in both motor control and motor imagery" (p. 1).

Also, applied experiments provided evidence that central integration of sensory input during PP affected MI durations, due to central updating of the temporal structure of the motor representation [15,22,25,26]. Di Rienzo et al. [26] observed that physical fatigue led to underestimation of the durations of imagined turns in swimming athletes. A tight temporal congruence between MI and PP was measured before fatigue state, but MI durations were shorter immediately after an intense swimming exercise. This was only observed for MI tasks that involved a strong reference to bodily information (i.e., first-person visual MI) [27]. Conversely, external visual imagery durations were unaffected by physical fatigue. The authors interpreted their results as an account of the update of the forward model due to the repeated integration of sensory feedbacks under fatigue state ([see also 23]). However, findings might also account for aversive or motivational effects related to the experience of physical fatigue. Finally, scientific data in clinical populations also support the hypothesis of sensory afferences playing a crucial role in the shaping of MI durations (e.g., [28]).

While cognitive motor processes participate to the elaboration of the temporal structure of MI [29,30], Decety et al. [31] early stated that "MI involve[s] the same clock mechanism as the actual motor behavior", with reference to Keele et al. [32]. The authors observed that overestimation of MI durations in stroke patients might account for "an impairment in the central implementation of the clock" (i.e., in the sense of the internal clock) $[33,34]$. In other words, MI durations might not only depend on the temporal parameters of forward models but also from internal clock processes generally involved in time estimation ability. Since Hoagland [33], theoretical models for a human internal clock were conceptualized from animal research (for a review, see [35]). Internal clock models assume that temporal features are centrally represented on the basis of a physiological "pacemaker" producing pulses at a given rate (the lick rate was assumed to play the role of the pacemaker in rats, see [36]). The amount of pulses within a given time period would be summed, stored within working memory, and finally compared with a reference long-term memory model (for an overview, see $[34,37,38]$ ). Applied to motor control, Treisman et al. [39] provided evidence that an oscillator controlled temporal estimations in humans and was involved in the control of movement timing.

Interestingly, a large body of experimental data supports that heartbeats may be the physiological pacemaker of the internal clock in humans [38,40-43]. Namely, humans might non-consciously refer to their own heartbeats to achieve time estimations. This postulate accounts for the reported effects of physiological arousal on time estimation ability [33,41,44-47]. Albeit it was recently suggested that physiological arousal, but not heart rate per se, influenced time estimation in humans, thus putting into debate the concept of "internal pacemaker" [48], physiological arousal and heart rate remain highly correlated. Past experiments also demonstrated that physiological arousal affected MI durations (see [10] for a review). For instance, Louis et al. [49] observed that reduced body arousal elicited by relaxation resulted in longer MI durations compared to both aroused and baseline conditions. In the same vein, Gueugneau et al. [22] found that the duration of MI followed the circadian rhythms of arousal, i.e., longer MI durations were measured early in the morning and late in the evening (see also [50]). To summarize, findings of a relationship between physiological arousal and MI durations are congruent with the working hypothesis of internal clock processes being involved in the temporal organization of MI. Nonetheless, the cognitive interplay between internal clock processes and time parameters of forward models remains at this point incompletely understood.

Voluntary breath-holding (i.e., apnea) at rest is known to decrease heart rate both in air and water environments $[38,43,51,52]$. Bradycardia occurs in response to water immersion due to cardiovascular and metabolic changes triggered by the mammalian diving reflex [53-56]. In a pioneering study, Jamin et al. [43] observed that reduced physiological arousal during breath-holding caused an underestimation of the durations of static apneas by about $20 \%$. According to the authors, bradycardia disturbed the internal clock and impaired time estimation ability. These findings are of specific concern 
for breath-holders, because accurate control of the time spent under apnea is crucial to achieve safe practice and avoid syncope accidents [38].

The present study used the unique model of apnea to understand the respective contribution of $i$ ) time parameters of forward models derived from past motor experiences and ii) internal clock processes depending on the current physiological body state on the temporal features of MI. We hypothesized that breath-holding might affect MI durations due to changes in the internal clock, and that these effects would be selective according to the arousal body state during PP.

\section{Methods}

\section{Participants}

Fourteen breath-holding athletes were requested to physically and mentally perform a set of two swimming tasks, the first with, and the second without simultaneously holding breath. The experimental group consisted of 14 breath-holding athletes (males $=11$, females $=3$; $M=38.3, S D=7.7)$ and included both national $(n=9)$ and inter-regional $(n=5)$ athletes. The experimental design was approved by the Research Ethics Committee of the University. Informed written consent was obtained according to the principles and statements of the Declaration of Helsinki (1964).

\section{Experimental design and settings}

Experiments were individually implemented in a $25 \mathrm{~m}$ public swimming pool (F-69110, Sainte Foy-lès-Lyon). Water temperature was $27.3^{\circ} \mathrm{C}$ and participants wore an apnea suit and were not weighted. Three iron sticks were initially dived at the bottom of the pool, perpendicularly to the lane. Iron sticks were respectively separated from each other by 4.5, 3.0 and $1.5 \mathrm{~m}$ (Figure 1 ). All experimental sessions were carried out in the same daytime $(8 \mathrm{pm})$, i.e., when MI performance is the most accurate $[22,50]$.

\section{Swimming tasks}

Participants were requested to physically and mentally perform two swimming tasks of $15 \mathrm{~m}$ involving a sequence of aquatic displacements between 3 iron stick positions. The first task was a 1-3-1-2-1 sequence and the second was a 3-1-2-1-3 sequence (Figure 1). The first swimming task was performed while breathing normally using a scuba after a $45 \mathrm{~s}$ period of rest where participants breathed normally behind the starting iron stick (PP BREATHE). The second task was performed under apnea following a $45 \mathrm{~s}$ period of static apnea behind the starting iron stick $\left(\mathrm{PP}_{\mathrm{APNEA}}\right)$. Pilot recordings showed that this duration was sufficient to elicit a sustained bradycardia without eliciting any discomfort for participants. The two tasks were of equivalent difficulty and involved a similar number of turns. During both tasks, participants were instructed to swim using self-paced breaststroke actions, and to remain by the surface of the pool (i.e., a part of their body had to be constantly visible out of water surface by the experimenter). Concerning the turns, after the head had passed the iron stick, participants turned themselves and swam in the reverse direction. $\mathrm{PP}_{\text {BREATHE }}$ and $\mathrm{PP}_{\text {APNEA }}$ were presented in a randomized order across participants. Four PP trials were completed before measurements of MI durations.

The timekeeping of $\mathrm{PP}_{\text {BREATHE }}$ and $\mathrm{PP}_{\text {APNEA }}$ was manually performed by a professional swimming coach who was not informed of the purpose of the study.

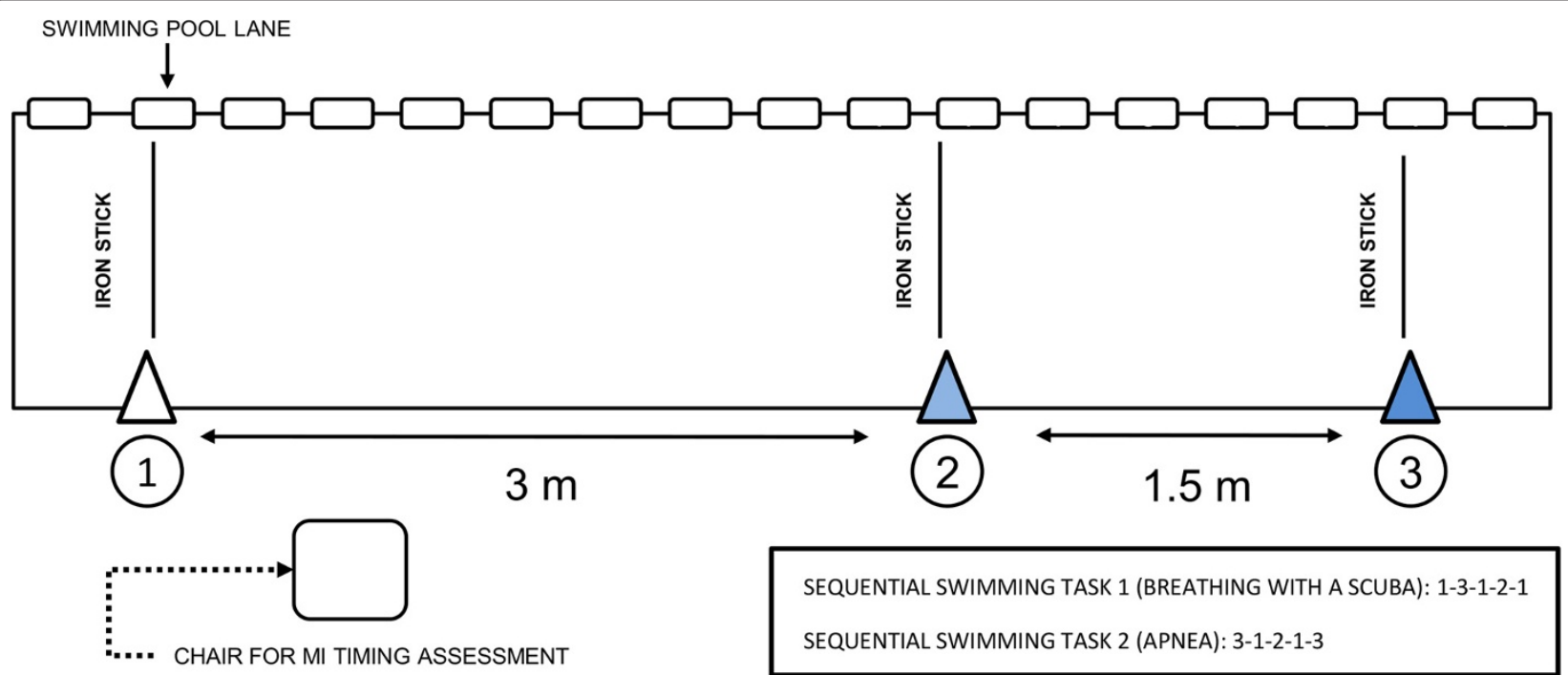

Figure 1 Overhead view of experimental settings for the two sequential swimming tasks. Ml: Motor Imagery. 
Timekeeping was triggered when breath-holder's head passed above the starting and ending iron sticks (i.e., 13-1-2-1 for PP BREATHE $_{\text {and } 3-1-2-1-3 \text { for PP }}$ APNEA (Figure 1).

\section{Motor imagery ability assessment}

Breath-holding participants completed, before the experiment, a validated MI questionnaire to assess their ability to engage into MI (MIQ-3 questionnaire) [57]. The MIQ-3 consists in 12 items for which participants rate the ease/difficulty encountered during MI on 7-point scales (ranging from 1: "very hard to see/feel" to 7: "very easy to see/feel") referring to external visual, internal visual, and kinesthetic MI.

Mental chronometry allows investigation of the time course of information processing within the central nervous system [58]. We measured MI duration immediately after PP of the corresponding motor task. Participants sat comfortably in a chair placed by the side of the swimming pool (Figure 1). Participants were instructed to perform MI of the sequence using first-person visual and kinesthetic MI concurrently. For PP $\mathrm{BREATHE}_{\mathrm{A}}$ and $\mathrm{PP}_{\text {APNEA }}$, they performed MI while breathing normally after a $45 \mathrm{~s}$ period of normal breathing (MI $\mathrm{MREATHE})$ and while holding breath after a $45 \mathrm{~s}$ period of static apnea $\left(\mathrm{MI}_{\mathrm{APNEA}}\right)$. The two MI conditions were presented in a randomized order (3 trials each). Participants orally indicated the onset and end of each MI trial.

After completion of $\mathrm{MI}_{\mathrm{BREATHE}}$ and $\mathrm{MI}_{\mathrm{APNEA}}$, participants reported their level of MI ease/difficulty on a 10point Lickert scale (ranging from 1: "very easy" to 10: "very hard").

\section{Cardiac activity}

We recorded the cardiac activity using a heart rate monitor (Polar ${ }^{\circ}$ RCX3, France) providing the instantaneous heart rate (IHR) in beats per minute (bpm). HR at rest $\left(\mathrm{HR}_{\mathrm{REST}}\right)$ was individually evaluated before the onset of experiments. $\mathrm{HR}_{\mathrm{REST}}$ was considered the average value obtained during $45 \mathrm{~s}$ of rest during which participants remained motionless, comfortably seated on the chair by the side of the pool (Figure 1).

Voluntary apnea with face immersion in humans is commonly associated with anticipatory tachycardia. Cardiac activity starts to decrease and stabilizes after approximately $30 \mathrm{~s}$ of face immersion (e.g., [59]). We could not monitor cardiac activity during the swimming tasks, which required a waterproof heart rate monitor. Yet, bradycardia in response to breath holding is largely documented in the literature, and is particularly marked due to the mammalian diving reflex $[51,53,56,60]$.

We collected the average HR during the $45 \mathrm{~s}$ period preceding $\mathrm{MI}$ and expressed it in percentage of $\mathrm{HR}_{\mathrm{REST}}$ for normalization across participants. We did not collect
HR data during MI due to solid literature background reporting MI-related changes in cardiac activity (i.e., cardiac responses during MI closely mirror physiological changes elicited by PP of the same task and/or recruitment of attentional resources) [61-64].

\section{Statistical analyses}

All statistical calculations were performed using the $\mathrm{R}$ freeware [65], and the alpha threshold for significance was settled at $\alpha=5 \%$.

MIQ-3 scores represent discrete variables derived from ordinal scales. Due to assumption of non-Gaussian distribution, they were compared across internal visual, external visual and kinesthetic MI modalities using Friedman's test. Self-reports of ease/difficulty were compared between $\mathrm{MI}_{\text {BREATHE }}$ and $\mathrm{MI}_{\mathrm{APNEA}}$ using paired Wilcoxon's tests.

Normality of chronometric data was checked through visual inspection of Q-Q plots. PP, $\mathrm{MI}_{\mathrm{BREATHE}}$ and $\mathrm{MI}_{\mathrm{APNEA}}$ durations were compared for both swimming tasks using a repeated measures MANOVA model with the swimming task as group factor ( $\mathrm{PP}_{\mathrm{BREATHE}}$ and $\mathrm{PP}_{\mathrm{APNEA}}$ ) and the task type as repetition factor (PP, $\mathrm{MI}_{\text {BREATHE }}$ and $\mathrm{MI}_{\text {APNEA }}$ ). An independent analysis of PP, $\mathrm{MI}_{\text {BREATHE }}$ and $\mathrm{MI}_{\mathrm{APNEA}}$ durations was conducted for PP $\mathrm{PREATHE}_{\mathrm{B}}$ and $\mathrm{PP}_{\mathrm{APNEA}}$ using one-way ANOVAs with repeated measures. We used paired Student's t-tests with Holm's Bonferroni corrections (Holm, 1969) for post-hoc comparisons.

For both swimming tasks, independence between HR and MI duration changes was tested using Pearson's product-moment correlation between the percentage of HR change before $\mathrm{MI}_{\text {BREATHE }}$ and $\mathrm{MI}_{\mathrm{APNEA}}$ and the percentage of change in $\mathrm{MI}_{\text {BREATHE }}$ and $\mathrm{MI}_{\mathrm{APNEA}}$ durations.

\section{Results}

\section{MIQ-3 scores}

Testing the MI modality effect on MIQ-3 scores did not reveal statistically significant differences (Friedman's Chi-squared $=1.45, p=.48$ ). Namely, breath-holders reported similar degrees of difficulty at performing external visual $(M=5.84, S D=.69)$, internal visual $(M=6.0$, $S D=.80)$ and kinesthetic MI $(M=5.80, S D=.97)$. Mean MIQ-3 scores $(M=5.80, S D=.59)$ also showed that participants experienced MIQ-3 tasks as easy to visualize or perceive.

\section{Likert ratings}

Breath holders self-reported greater MI ease scores during MI $_{\text {BREATHE }}(M=3.21, S D=.65)$ as compared to $\mathrm{MI}_{\text {APNEA }}$ $(M=4.93, S D=.70)$ when imagining the PP BREATHE task (Wilcoxon's $W=3.5, p=.005$ ). Conversely, lower ratings were obtained during $\mathrm{MI}_{\mathrm{APNEA}}(M=3.58, S D=.62) \mathrm{com}$ pared to $\mathrm{MI}_{\text {BREATHE }}(M=5.15, S D=.52)$ when imagining the $\mathrm{PP}_{\text {APNEA }}$ swimming task (Wilcoxon's $W=44, p=.01$ ). 


\section{Temporal data}

MANOVA with repeated measures yielded the main effect of Task $\left(F_{(2,25)}=10.16, p<.001, \eta^{2}=.44\right)$ while there was a trend concerning the interaction between the swimming task and task type $\left(F_{(2,25)}=2.96, p=.06, \eta^{2}=.12\right)$.

ANOVA with repeated measures revealed that the effect of task type was statistically significant for both $\mathrm{PP}_{\text {BREATHE }}$ and $\mathrm{PP}_{\text {APNEA }}\left(F_{(2,26)}=4.19, p=.02\right.$ and $F_{(2,26)}=$ $20.44, p<.001$, respectively). For both swimming tasks, post-hoc analyses revealed higher durations during PP compared to $\mathrm{MI}_{\text {BREATHE }}(p=.02$ and $p<.001$, respectively), as well as during $\mathrm{MI}_{\mathrm{APNEA}}$ compared to $\mathrm{MI}_{\mathrm{BREATHE}}$ $(p=.02)$ as shown by Figure 2 . Post-hoc analyses also revealed shorter durations during $\mathrm{MI}_{\text {APNEA }}(M=27.71$, $S D=8.18)$ compared to $\mathrm{PP}_{\text {BREATHE }}(M=31.02, S D=7.15$; $p<.001)$, whereas no difference emerged between $\mathrm{MI}_{\mathrm{APNEA}}$ $(M=29.78, S D=9.95)$ and $\mathrm{PP}_{\text {APNEA }}(M=29.79, S D=6.73)$ $(p=.99)$. As there was no difference between $\mathrm{PP}_{\mathrm{BREATHE}}$ and $\mathrm{PP}_{\mathrm{APNEA}}$ durations $(p=.72)$, the patterns of MI $v s$. PP differences in durations across swimming tasks might account for the trend in the MANOVA model, albeit the difference between the two $\mathrm{MI}_{\mathrm{APNEA}}$ durations was only marginally significant when corrections for multiple comparisons were applied $(M=2.07 \mathrm{~s}, S D=3.47, p=.09)$, see Figure 2. Finally, the difference in durations between $\mathrm{MI}_{\text {BREATHE }}$ of the $\mathrm{PP}_{\mathrm{BREATHE}}$ and $\mathrm{PP}_{\mathrm{APNEA}}$ tasks was far from significance $(p=.98)$ as shown by Figure 1 .

\section{Cardiac activity}

HR data were processed from 13 participants as data from one participant was lost due to a technical failure. Overall, average $\mathrm{HR}$ before $\mathrm{MI}_{\mathrm{BREATHE}}$ was $72.61 \mathrm{bpm}(S D=2.29)$ while average $\mathrm{HR}$ before $\mathrm{MI}_{\mathrm{APNEA}}$ was $66.81 \mathrm{bpm}(S D=2.24)$. Significant differences were observed in HR before the onset of the two MI conditions for both PP $\mathrm{BREATHE}_{\mathrm{B}}$ (7.0\% of $\mathrm{HR}_{\text {REST }}$ decrease at onset of $\mathrm{MI}_{\mathrm{APNEA}}$ as compared to $\mathrm{MI}_{\mathrm{BREATHE}} ; t=3.91, \mu=0$, $p=.002)$ and $\mathrm{PP}_{\text {APNEA }}$ (9.0\% of $\mathrm{HR}_{\mathrm{REST}}$ decrease at onset of $\mathrm{MI}_{\mathrm{APNEA}}$ as compared to $\mathrm{MI}_{\mathrm{BREATHE}} ; \mathrm{t}=4.27, \mu=0$, $\mathrm{p}=.001)$.

A correlation between the percentage of $\mathrm{HR}$ decrease between periods preceding $\mathrm{MI}_{\mathrm{BREATHE}}$ and $\mathrm{MI}_{\mathrm{APNEA}}$ and the percentages of $\mathrm{MI}$ durations increase between $\mathrm{MI}_{\text {BREATHE }}$ and $\mathrm{MI}_{\text {APNEA }}$ was found for both PP $\mathrm{PREATHE}_{\mathrm{B}}$ and $\mathrm{PP}_{\mathrm{APNEA}}\left(R^{2}=.80, p<.001\right.$ and $R^{2}=.48, p<.01$, respectively). The sum square error of the regression was $66 \%$ higher for $\mathrm{PP}_{\mathrm{BREATHE}}$ compared to $\mathrm{PP}_{\mathrm{APNEA}}$ (Figure 3).

\section{Discussion}

The present study was designed to investigate the effect of apnea on MI duration, and understand the respective contribution of the temporal parameters of both forward models and internal clock processes to the elaboration of the temporal structure of MI. We assessed participants ability to engage into MI using a validated MI questionnaire [57]. We recorded the durations of two swimming tasks performed with and without holding breath. For each task, we combined chronometric and physiological recordings of MI performed with and without holding breath.

MIQ-3 scores were similar between external visual, internal visual and kinesthetic imagery modalities. We specifically instructed participants to engage into firstperson and kinesthetic MI concurrently as these modalities involve greater reference to one's procedural memory

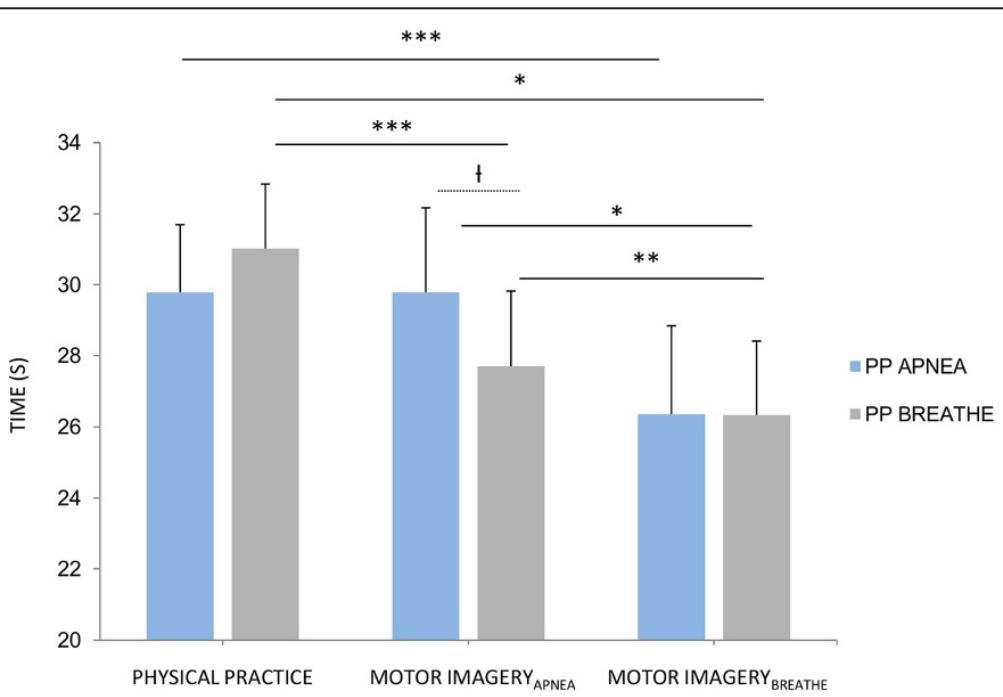

Figure 2 Physical practice and motor imagery durations during breathing and apnea swimming tasks. Error bars represent mean standard error. Only significant differences were graphically represented. PP: Physical Practice. t: $p<.10,{ }^{*}: p<.05,{ }^{* *}: p<.01,{ }^{* * *}: p<.001$. 


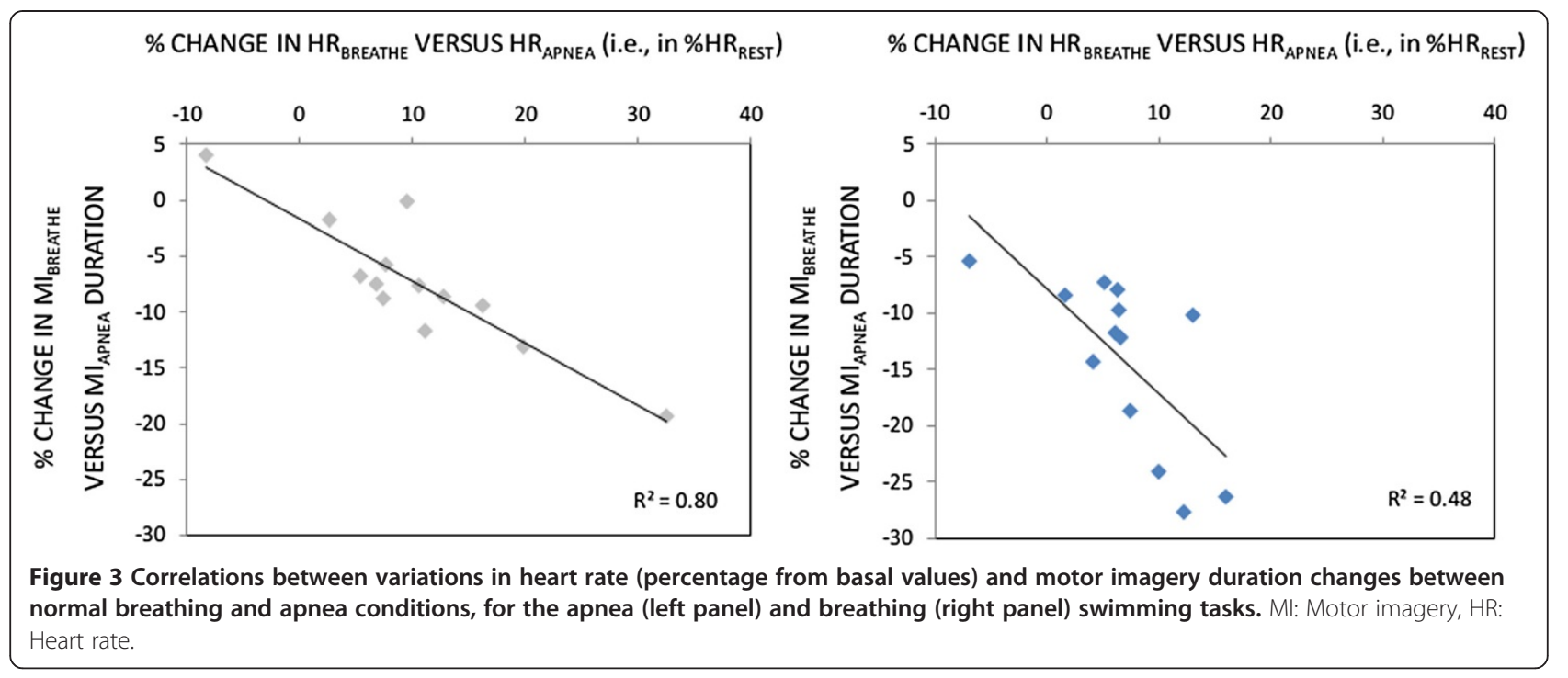

$[26,27]$. No significant difference was found between the durations of the two swimming tasks. Both were physically performed using a similar swimming technique, involved the same number of turns and a similar distance. Interestingly, $\mathrm{PP}_{\text {BREATHE }}$ durations were underestimated during MI BREATHE. This result might account for the characteristics of the swimming sequence. Indeed, PP of both sequences lasted about $30 \mathrm{~s}$. As recently reviewed by Guillot et al. [10], motor sequences longer than 15-20 s tend to be underestimated (e.g., [17,66-68]). The reasons supporting this effect are not straightforward. Temporal parameters of movements may be quantitatively more complex to reproduce accurately in the case of long motor sequences, particularly for actions requiring an important amount of feedback control with reference to the action/control model by Glover [69]:

\section{"(...) the control of nonballistic actions is achieved by continuously regulating the movement during its execution so that the desired end state is achieved at the desired time. The lack of this information in imagery may be what causes a shortening of the duration of the imagined event" [66], p. 880.}

Due to the solid literature background supporting that motor experiences shape the temporal organization of MI $[22,23,25,28]$, similar imagined durations were expected between the two swimming tasks. However, $M_{\text {APNEA }}$ exceeded $\mathrm{MI}_{\text {BREATHE }}$ durations regardless the swimming task involved. Performing MI while holding breath overall increased MI durations by $2.7 \mathrm{~s}(\approx 10 \%)$. Importantly, increased MI durations under the condition of breath-holding were correlated to the preceding HR decrease. This relationship was observed for both swimming tasks (Figure 3). These findings support the involvement of internal clock processes in the shaping of MI duration, as early postulated by Decety et al. [31]. As time perception and movement timing both involve reference to a common physiological oscillator [36,39], it is suggested that bradycardia affected the internal clock "pacemaker" [34,35,38,40-42], thus slowing the processing rate of motor representations. The involvement of the internal clock in the generation of MI durations brings new insights for a unified interpretation of experimental results related to factors affecting MI durations, such as the circadian modulation $[22,50]$ or relaxed/aroused body states [49]. Interestingly, these studies reported increased MI durations under low physiological arousal and shortened MI durations under high physiological arousal. These changes were typically associated with different cardiac activities $[26,49]$.

$\mathrm{MI}_{\text {APNEA }}$ durations remained shorter than that of PP for the swimming task involving normal breathing, whereas isochrony was found when comparing $\mathrm{MI}_{\mathrm{APNEA}}$ and apnea swimming task durations. Longer durations $(+2.07 \mathrm{~s})$ were recorded during $\mathrm{MI}_{\mathrm{APNEA}}$ of the apnea swimming tasks vs. $\mathrm{MI}_{\mathrm{APNEA}}$ of the swimming task performed while breathing with a scuba. Yet, this difference was only marginally significant when corrections for multiple comparisons were applied (Figure 2). This unexpected finding suggests that congruence in physiological body states between overt and covert motor performance also contributes to the accuracy of MI durations. A limitation to this interpretation is that we did not record isochrony between $\mathrm{MI}_{\text {BREATHE }}$ and $\mathrm{PP}_{\text {BREATHE}}$. This mismatch was attributed to the task duration, thought to elicit an incomplete encoding of the temporal parameters $[10,66]$. The apnea swimming task was of identical duration but, crucially, was performed under a state of reduced physiological arousal. As movement 
timing parameters are controlled through reference to the internal clock [39], retention of movement timing parameters may be facilitated under the condition of reduced physiological arousal eliciting a slowing down of the internal clock $[38,43]$. While the underestimation of $\mathrm{MI}_{\text {BREATHE }}$ durations might account for the task duration in the case of normal breathing, it may rather relate to the physiological arousal mismatch during $\mathrm{MI}_{\text {BREATHE }}$ of the apnea swimming task. Albeit this interpretation remains an inference, forward models relate to current body states through integration of proprioceptive afferences $[27,70]$. For instance, the physiological body state affects the body representation through subtle changes in proprioceptive inputs to the central nervous system (see $[71,72]$ for examples). Therefore, the arousal state is an intrinsic component of the central processing of the expected consequences of imagined actions (forward modeling). Overall, while reference to internal clock affected the processing rate of motor representations, accurate movement timing processing through forward modeling presumably required a state of congruence in physiological body states. The fact that the R-squared of the regression between changes in HR and the associated changes in MI durations was higher (66\%) for the breathing compared to the non-breathing swimming task partly supports to this assumption, as in the latter case online changes in the internal clock accounted to a lesser extent for the associated changes in MI durations.

Isochrony between $\mathrm{MI}_{\mathrm{APNEA}}$ and $\mathrm{PP}_{\mathrm{APNEA}}$ may thus result from both efficient storage of timing parameters of actual movement, facilitated by the changes in the internal clock in response to apnea, and accurate processing of the expected sensory consequences of the imagined action due to congruence in physiological body states. Such assumption is congruent with the subjective reports. Breath holders reported greater MI ease when the physiological arousal condition before initiation of MI was similar to that preceding PP of the same task (i.e., namely with or without holding breath during the $45 \mathrm{~s}$ preceding initiation of MI or PP). These preliminary results support the co-contribution of forward modeling and internal clock processes to the shaping of MI duration. Yet, this preliminary study must be extended by future designs involving different levels of arousal (e.g., increased heart rate) and retention conditions (e.g., performing MI two days later). Complementary measurement of physiological arousal are also necessary (e.g., autonomic nervous system recordings), for instance under the conditions of MI and apnea underwater [73,74]. Another interesting issue would be determining to which extent changes in cerebral blood flow due to apnea might affect MI ability. For instance, accurate MI duration was associated with higher activation intensities within regions of the brain motor system [75]. As previous work underlined that apnea led to the underestimation of PP duration $[38,43]$, future studies should seek to determine whether correcting the effect of breath holding on MI durations (i.e., involving biased temporal predictions related to bradycardia amplitude), for instance by providing feedback concerning respect of isochrony with PP after completion of MI, would improve time estimation accuracy. Taken together, present findings might contribute to promote safe apnea practice in the currently developing context of apnea competitions.

\section{Competing interests}

The authors declare no competing interests.

\section{Authors' contributions}

All authors (FDR, NH, CC and AG) participated to the design of the study. FDR and NH supervised the experiments. FDR performed the statistical analyses and drafted the manuscript. All authors read, amended and approved the final manuscript.

\section{Acknowledgements}

We gratefully acknowledge the $\mathrm{H}_{2} \mathrm{O}$ apnea sporting club (Sainte-Foy-lès-Lyon, F-69110) and the Aquatic Club Fidésien apnea elite team (Sainte-Foy-lès-Lyon, F-69110) for their human and material support.

\section{Author details}

'Centre de Recherche et d'Innovation sur le Sport, EA 647, Université de Lyon, Université Claude Bernard, Lyon 1, Performance Motrice, Mentale et du Matériel (P3M), 27-29 Boulevard du 11 Novembre 1918, Villeurbanne, Cedex 69622, France. ${ }^{2}$ Institut Universitaire de France, 103 boulevard Saint-Michel, Paris 75005, France.

Received: 7 January 2014 Accepted: 15 April 2014 Published: 28 April 2014

\section{References}

1. Ehrsson HH, Geyer S, Naito E: Imagery of voluntary movement of fingers, toes, and tongue activates corresponding body-part-specific motor representations. J Neurophysiol 2003, 90:3304-3316.

2. Szameitat AJ, Shen S, Sterr A: Motor imagery of complex everyday movements. An fMRI study. Neuroimage 2007, 34:702-713.

3. Michelon P, Vettel JM, Zacks JM: Lateral somatotopic organization during imagined and prepared movements. J Neurophysiol 2006, 95:811-822.

4. Guillot A, Di Rienzo F, Collet C: The neurofunctional architecture of motor imagery. In Functional magnetic resonance imaging/Book 1, In Tech. Edited by Papageorgiou TD, Christopoulos G, Smirnakis S. 2014.

5. Jeannerod M: Mental imagery in the motor context. Neuropsychologia 1995, 33:1419-1432.

6. Jeannerod M: The representing brain: neural correlates of motor intention and imagery. Behav Brain Sci 1994, 17:187-202.

7. Holmes PS, Collins DJ: The PETTLEP approach to motor imagery: a functional equivalence model for sport psychologists. J Appl Sport Psychol 2001, 13:60-83.

8. Gao Q, Duan X, Chen $\mathrm{H}$ : Evaluation of effective connectivity of motor areas during motor imagery and execution using conditional Granger causality. Neuroimage 2011, 54:1280-1288.

9. Decety J, Michel F: Comparative analysis of actual and mental movement times in two graphic tasks. Brain Cogn 1989, 11:87-97.

10. Guillot A, Hoyek N, Louis M, Collet C: Understanding the timing of motor imagery: recent findings and future directions. Int Rev Sport Exerc Psychol 2012, 5:3-22.

11. Beyer $L$, Weiss $T$, Hansen $E$, Wolf $A$, Seidel A: Dynamics of central nervous activation during motor imagination. Int J Psychophysiol 1990, 9:75-80.

12. Maruff $P$, Velakoulis $D$ : The voluntary control of motor imagery. Imagined movements in individuals with feigned motor impairment and conversion disorder. Neuropsychologia 2000, 38:1251-1260. 
13. Cerritelli $B$, Maruff $P$, Wilson $P$, Currie J: The effect of an external load on the force and timing components of mentally represented actions. Behav Brain Res 2000, 108:91-96.

14. Slifkin $A B$ : High loads induce differences between actual and imagined movement duration. Exp Brain Res 2008, 185:297-307.

15. Papaxanthis C, Schieppati M, Gentili R, Pozzo T: Imagined and actual arm movements have similar durations when performed under different conditions of direction and mass. Exp Brain Res 2002, 143:447-452.

16. Olsson CJ, Nyberg L: Motor imagery: if you can't do it, you won't think it Scand J Med Sci Sports 2010, 20:711-715.

17. Guillot A, Collet C: Duration of mentally simulated movement: a review. J Mot Behav 2005, 37:10-20.

18. Wolpert DM, Flanagan JR: Motor prediction. Curr Biol: CB 2001, 11:R729-R732

19. Miall R, Wolpert DM: Forward models for physiological motor control. Neural Netw 1996, 9:1265-1279.

20. Wolpert DM, Ghahramani Z: Computational principles of movement neuroscience. Nat Neurosci 2000, 3(Suppl):1212-1217.

21. Grush R: The emulation theory of representation: motor control, imagery, and perception. Behav Brain Sci 2004, 27:377-396.

22. Gueugneau N, Mauvieux B, Papaxanthis C: Circadian modulation of mentally simulated motor actions: implications for the potential use of motor imagery in rehabilitation. Neurorehabil Neural Repair 2009, 23:237-245.

23. Demougeot $L$, Papaxanthis $C$ : Muscle fatigue affects mental simulation of action. J Neurosci 2011, 31:10712-10720.

24. Lorey B, Pilgramm S, Walter B, Stark R, Munzert J, Zentgraf K: Your mind's hand: motor imagery of pointing movements with different accuracy. Neuroimage 2010, 49:3239-3247.

25. Gueugneau N, Papaxanthis C: Time-of-day effects on the internal simulation of motor actions: psychophysical evidence from pointing movements with the dominant and non-dominant arm. Chronobiol Int 2010, 27:620-639.

26. Di Rienzo F, Collet C, Hoyek N, Guillot A: Selective effect of physical fatigue on motor imagery accuracy. PLoS One 2012, 7:e47207.

27. Lorey B, Bischoff M, Pilgramm S, Stark R, Munzert J, Zentgraf K: The embodied nature of motor imagery: the influence of posture and perspective. Exp Brain Res Exp 2009, 194:233-243.

28. Liepert J, Greiner J, Nedelko V, Dettmers C: Reduced upper limb sensation impairs mental chronometry for motor imagery after stroke: clinical and electrophysiological findings. Neurorehabil Neural Repair 2012, 26(5):470-478.

29. Toussaint $L$, Robin N, Blandin Y: On the content of sensorimotor representations after actual and motor imagery practice. Mot Control 2010, 14:159-175.

30. Toussaint M: A sensorimotor map: modulating lateral interactions for anticipation and planning. Neural Comput 2006, 18:1132-1155.

31. Decety J, Boisson D: Effect of brain and spinal cord injuries on motor imagery. Eur Arch Psychiatry Clin Neurosci 1990, 240:39-43.

32. Keele SW, Pokorny RA, Corcos DM, Ivry R: Do perception and motor production share common timing mechanisms: A correlational analysis. Acta Psychol (Amst) 1985, 60:173-191.

33. Hoagland $\mathrm{H}$ : The physiological control of judgments of duration: evidence for a chemical clock. J Gen Psychol 1933, 9:267-287.

34. Church RM: Properties of the internal clock. Ann N Y Acad Sci 1984 423:566-582.

35. Church RM, Guilhardi P, Keen R, MacInnis M, Kirkpatrick K: Simultaneous temporal processing. In Time and Mind II: Information Processing Perspectives. Edited by H. Helfrich. Gottingen, Germany: Hogrefe \& Huber Publishers; 2003:3-19.

36. Treisman M: Temporal rhythms and cerebral rhythms. Ann NY Acad Sci 1984, 423:542-565.

37. Meck WH, Church RM: Simultaneous temporal processing. J Exp Psychol Anim Behav Process 1984, 10:1-29.

38. Jamin T, Joulia F, Fontanari P, Giacomoni M, Bonnon M, Vidal F, Cremieux J: Apnea-induced changes in time estimation and its relation to bradycardia. Aviat Space Environ Med 2004, 75:876-880.

39. Treisman M, Faulkner $A$, Naish PL: On the relation between time perception and the timing of motor action: evidence for a tempora oscillator controlling the timing of movement. Q J Exp Psychol 1992, 45:235-263.

40. Cahoon RL: Effect of acute exposure to altitude on time estimation. J Psychol 1967, 66:321-324.
41. Cahoon RL: Physiological arousal and time estimation. Percept Mot Skills 1969, 28:259-268.

42. Osato E, Ogawa N, Takaoka N: Relations among heart rate, immediate memory, and time estimation under two different instructions. Percept Mot Skills 1995, 80:831-842

43. Jamin $T$, Joulia F, Fontanari $P$, Bonnon M, Ulmer C, Crémieux J: Effect of a static apnea exposure on time estimation ability. Sci Sports 2004, 19:142-144.

44. Gulliksen $\mathrm{H}$ : The influence of occupation upon the perception of time. J Exp Psychol 1927, 10:52

45. Bell C: Control of time estimation by a chemical clock. Nature 1966 210:1189.

46. Vercruyssen M, Hancock $P$, Mihaly T: Time estimation performance before, during, and following physical activity. J Hum Ergol 1989, 18:169-179.

47. Wearden $\mathrm{JH}$, Penton-Voak IS: Feeling the heat: body temperature and the rate of subjective time, revisited. Q J Exp Psychol 1995, 48:129-141.

48. Schwarz MA, Winkler I, Sedlmeier P: The heart beat does not make us tick: The impacts of heart rate and arousal on time perception. Atten Percept Psychophys 2013, 75:182-193

49. Louis $M$, Collet $C$, Guillot A: Differences in motor imagery times during aroused and relaxed conditions. J Cognit Psychol 2011, 23:374-382.

50. Debarnot U, Sahraoui D, Champely S, Collet C, Guillot A: Selective influence of circadian modulation and task characteristics on motor imagery time. Res Q Exerc Sport 2012, 83:442-450.

51. Manley L: Apnoeic heart rate responses in humans. A review. Sports Med (Auckland, NZ) 1990, 9:286-310.

52. Foster GE, Sheel AW: The human diving response, its function, and its control. Scand J Med Sci Sports 2005, 15:3-12.

53. Paulev PE: Cardiac rhythm during breath-holding and water immersion in man. Acta Physiol Scand 1968, 73:139-150.

54. Bergman SA, Campbell J, Wildenthal K: "Diving reflex" in man: its relation to isometric and dynamic exercise. J App/ Physiol 1972, 33:27-31.

55. Schagatay $E_{1}$ Holm B: Effects of water and ambient air temperatures on human diving bradycardia. Eur J Appl Physiol Occup Physiol 1996, 73:1-6.

56. Andersson J, Schagatay E, Gislén A, Holm B: Cardiovascular responses to cold-water immersions of the forearm and face, and their relationship to apnoea. Eur J Appl Physiol 2000, 83:566-572.

57. Williams SE, Cumming J, Ntoumanis N, Nordin-Bates SM, Ramsey R, Hall C: Further validation and development of the movement imagery questionnaire. J Sport Exerc Psychol 2012, 34:621-646.

58. Posner Ml: Chronometric explorations of mind. Hillsdale, NJ: Erlbaum; 1978.

59. Schagatay E, Andersson JPA, Hallén M, Pålsson B: Selected contribution: role of spleen emptying in prolonging apneas in humans. J Appl Physiol 2001, 90:1623-1629.

60. Przybylowski T, Bangash MF, Reichmuth K, Morgan BJ, Skatrud JB, Dempsey JA: Mechanisms of the cerebrovascular response to apnoea in humans. J Physiol 2003, 548:323-332.

61. Decety J, Jeannerod M, Germain M, Pastene J: Vegetative response during imagined movement is proportional to mental effort. Behav Brain Res 1991, 42:1-5.

62. Decety J, Jeannerod M, Durozard D, Baverel G: Central activation of autonomic effectors during mental simulation of motor actions in man. J Physiol 1993, 461:549-563.

63. Guillot A, Collet C: Contribution from neurophysiological and psychological methods to the study of motor imagery. Brain Res Rev 2005, 50:387-397.

64. Collet C, Guillot A, Lebon F, Maclntyre T, Moran A: Measuring motor imagery using psychometric, behavioral, and psychophysiological tools. Exerc Sport Sci Rev 2011, 39:85-92.

65. Core Team R: R: A language and environment for statistical computing. Vienna, Austria: R Foundation for Statistical Computing; 2014.

66. Grealy MA, Shearer GF: Timing processes in motor imagery. Eur J Cogn Psychol 2008, 20:867-892.

67. Hanyu K, Itsukushima Y: Cognitive distance of stairways distance, traversal time, and mental walking time estimations. Environ Behav 1995, 27:579-591.

68. Hanyu K, Itsukushima Y: Cognitive distance of stairways: a multi-stairway investigation. Scand J Psychol 2000, 41:63-70.

69. Glover S: Separate visual representations in the planning and control of action. Behav Brain Sci 2004, 27:3-24.

70. Sirigu A, Duhamel J: Motor and visual imagery as two complementary but neurally dissociable mental processes. J Cogn Neurosci 2001, 13:910-919. 
71. Kanekar N, Santos MJ, Aruin AS: Anticipatory postural control following fatigue of postural and focal muscles. Clin Neurophysiol 2008, 119:2304-2313.

72. Paillard T: Effects of general and local fatigue on postural control: a review. Neurosci Biobehav Rev 2012, 36:162-176.

73. Hemelryck W, Rozloznik M, Germonpre P, Balestra C, Lafere P: Functional comparison between critical flicker fusion frequency and simple cognitive tests in subjects breathing air or oxygen in normobaria. Diving Hyperb Med J South Pac Underwater Med Soc 2013, 43:138-142.

74. Balestra C, Lafere P, Germonpre P: Persistence of critical flicker fusion frequency impairment after a $33 \mathrm{mfw}$ SCUBA dive: evidence of prolonged nitrogen narcosis? Eur J Appl Physiol 2012, 112:4063-4068.

75. van der Meulen M, Allali G, Rieger SW, Assal F, Vuilleumier P: The influence of individual motor imagery ability on cerebral recruitment during gait imagery. Hum Brain Mapp 2014, 35:455-470.

doi:10.1186/1744-9081-10-15

Cite this article as: Di Rienzo et al:: Physiological changes in response to apnea impact the timing of motor representations: a preliminary study. Behavioral and Brain Functions 2014 10:15.

\section{Submit your next manuscript to BioMed Central and take full advantage of:}

- Convenient online submission

- Thorough peer review

- No space constraints or color figure charges

- Immediate publication on acceptance

- Inclusion in PubMed, CAS, Scopus and Google Scholar

- Research which is freely available for redistribution 